\title{
SYNCHRONOUS GENERATOR MODEL PARAMETER ESTIMATION BASED ON NOISY DYNAMIC WAVEFORMS
}

\author{
Sebastian Berhausen — Stefan Paszek *
}

\begin{abstract}
In recent years, there have occurred system failures in many power systems all over the world. They have resulted in a lack of power supply to a large number of recipients. To minimize the risk of occurrence of power failures, it is necessary to perform multivariate investigations, including simulations, of power system operating conditions. To conduct reliable simulations, the current base of parameters of the models of generating units, containing the models of synchronous generators, is necessary. In the paper, there is presented a method for parameter estimation of a synchronous generator nonlinear model based on the analysis of selected transient waveforms caused by introducing a disturbance (in the form of a pseudorandom signal) in the generator voltage regulation channel. The parameter estimation was performed by minimizing the objective function defined as a mean square error for deviations between the measurement waveforms and the waveforms calculated based on the generator mathematical model. A hybrid algorithm was used for the minimization of the objective function. In the paper, there is described a filter system used for filtering the noisy measurement waveforms. The calculation results of the model of a $44 \mathrm{~kW}$ synchronous generator installed on a laboratory stand of the Institute of Electrical Engineering and Computer Science of the Silesian University of Technology are also given. The presented estimation method can be successfully applied to parameter estimation of different models of high-power synchronous generators operating in a power system.
\end{abstract}

K e y w or ds: parameter estimation, synchronous generator in power system, pseudorandom signals PRBS, zero-phase waveform filtering, laboratory measurements

\section{INTRODUCTION}

Determination of suitable models and reliable parameters of all generating units included in the analyzed power system (PS) is the basis for carrying out reliable simulation calculations, including investigations of the PS angular stability. The base of synchronous generator mathematical model parameters whose values are obtained from catalog and design data delivered by manufacturers or are assessed based on the typical data published in scientifictechnical studies is often used for these investigations. Such parameter values are approximate, loaded with a big error in many cases, and they do not correspond to the true values of the parameters of exploited generating units. The parameter values delivered by manufacturers do not take into account the actual operating conditions, including changes of their properties caused by long-term operation, repairs and modernization aimed at increasing the rated power of a machine. For these reasons, in recent years there has been increased interest in scientificresearch centers in the issue of determining electromagnetic parameters of synchronous generators.

The measurement methods for determining parameters of synchronous generators can be divided into two basic groups: the methods using the results of measurements at the machine standstill [1-5] and the methods using the results of measurements at the rotating machine $[6-12]$.
In the parameter estimation methods of synchronous generators using the results of measurements taken at the machine standstill, the generator has to be switched off so these methods are safe to carry out. However, due to small (significantly different from rated) values of measurement signals, the determined parameters do not take into account the saturation of magnetic cores.

The methods using the results of measurements at the rotating machine, eg at load rejection or change in the voltage regulator reference voltage, do not have these disadvantages [9,13-15].

Besides the methods using measurement results, there are also developing computational methods that enable determining the machine parameters based on construction and design data. In these methods there are used, among others, electromagnetic field space distributions calculated by the finite element method $[16,17]$. The detailed knowledge of geometric and material data that are not always available is required to perform such analyses.

This paper focuses on calculating the parameters of the model a low-power synchronous generator installed in a laboratory of the Institute of Electrical Engineering and Computer Science of the Silesian University of Technology.

The transient waveforms caused by introducing a small disturbance in the form of an additional pseudorandom signal PRBS (Pseudo Binary Random Sequence) in the

* Silesian University of Technology, Faculty of Electrical Engineering, Institute of Electrical Engineering and Computer Science, ul. Akademicka 10, 44-100 Gliwice, Poland, sebastian.berhausen@polsl.pl, stefan.paszek@polsl.pl 


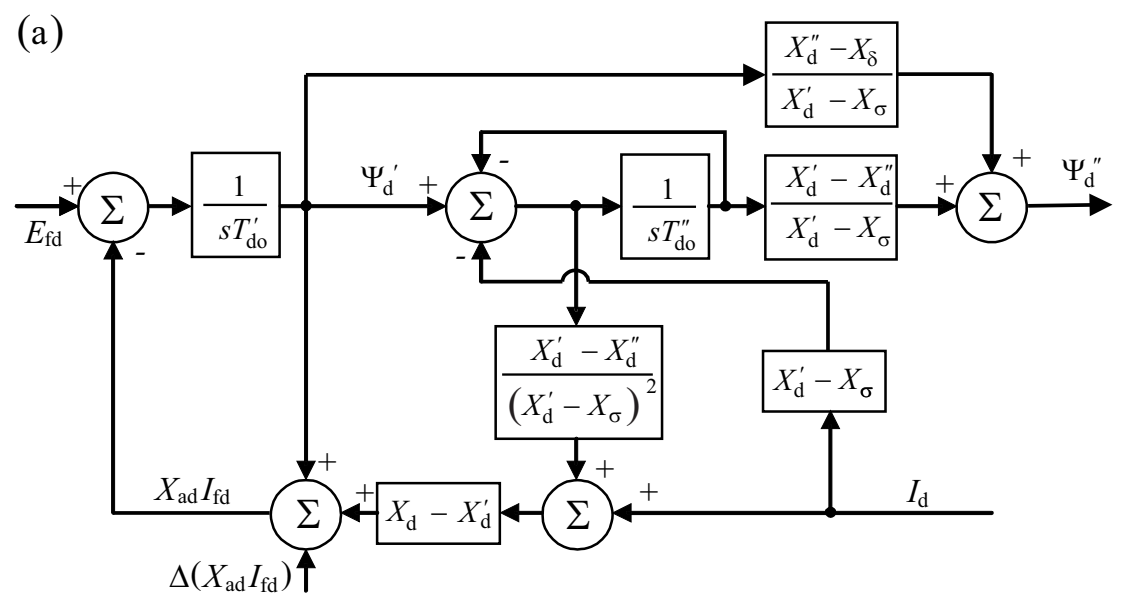

(b)

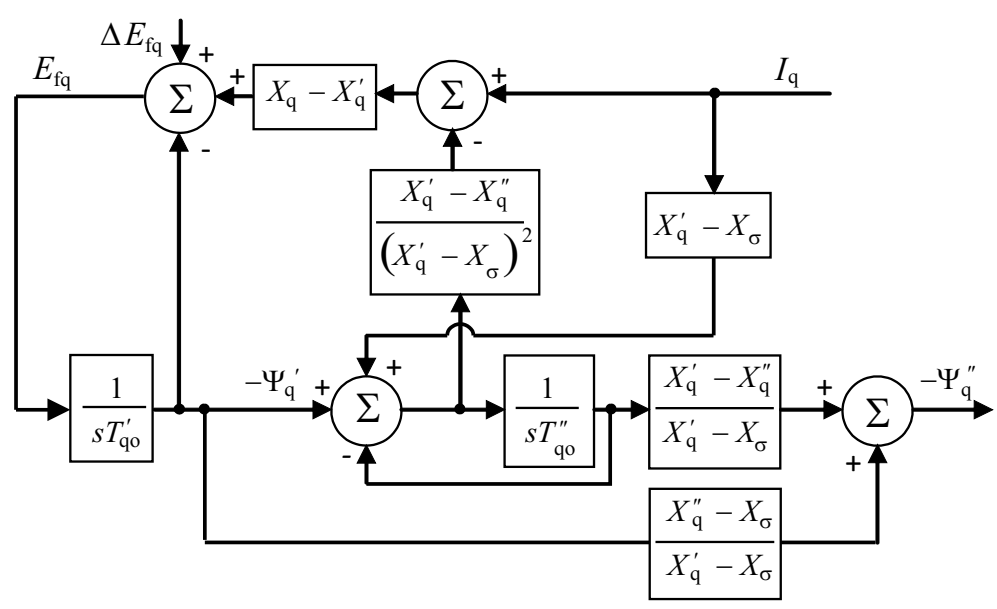

(c)

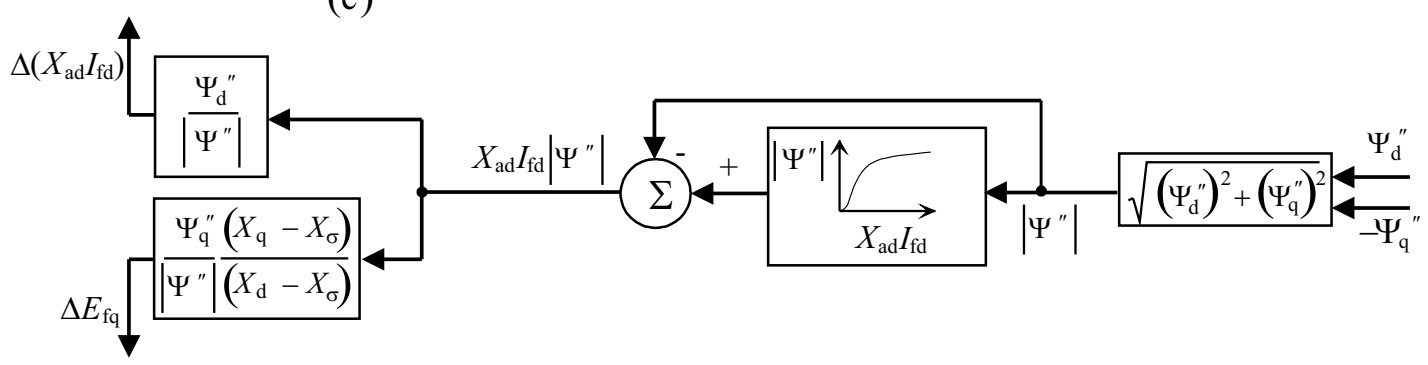

Fig. 1. Structural diagram of the synchronous generator model GENROU: (a) - in d-axis, (b) — in q-axis, (c) — including saturation of magnetic cores

generator voltage regulation channel are the basis of generator model parameter calculations $[10,14,18,19]$.

For the analyzed generator, suitable measurement tests were performed, electrical and mechanical signals were measured in steady and transient states and the parameters of the tested generator model were determined by the analysis of those measurement signals.

The parameters obtained from the estimation were compared (and verified) with the selected electromagnetic parameters of the generator calculated by the other methods. The calculations of the parameters $X_{\mathrm{d}}$ and $X_{\mathrm{q}}$ were verified by the analysis of no-load and three-phase shortcircuit characteristics as well as the use of the small slip method. The calculations of the stator resistance were checked by measurement of this resistance with the technical method.

The method presented in the paper can be applied to parameter estimation of the models of high-power synchronous generators operating in a power system.

This work is a continuation and expansion of the work: Assessment of the accuracy of synchronous generator model parameter estimation based on noisy dynamic waveforms [14], in which there was performed the analysis of the parameter estimation on the example of the test simulation model of a generating unit operating in a PS. 


\section{THE METHODOLOGY OF INVESTIGATIONS}

The parameters of the synchronous generator mathematical model (in d- and q-axis) can be determined based on the dynamic waveforms caused by a disturbance of the steady operation of a generator cooperating with a power network. This test consists in introducing a small component of the reference voltage in the form of a pseudorandom signal PRBS. The introduced disturbance resulted in changes of the waveforms of: currents and voltages of the stator in the direct and quadrature axes, the excitation current, the rotor angular speed and the machine load angle.

The synchronous generator parameter estimation was carried out for the nonlinear mathematical model GENROU [20], expressed by standard reactances and time constants of the steady, transient and subtransient state. Figure 1 shows the structural diagram of the synchronous generator model GENROU. The denotations in Fig. 1 are as follows: $V_{\mathrm{d}}, V_{\mathrm{q}}, I_{\mathrm{d}}, I_{\mathrm{q}}, \Psi_{\mathrm{d}}^{\prime \prime}, \Psi_{\mathrm{q}}^{\prime \prime}, \Psi_{\mathrm{d}}^{\prime}, \Psi_{\mathrm{q}}^{\prime}$ voltages, currents, subtransient and transient magnetic flux linkages of the stator in d- and q-axis, $E_{\mathrm{fd}}, I_{\mathrm{fd}}$ field voltage and excitation current, $X_{\sigma}, X_{\mathrm{d}}, X_{\mathrm{q}}, X_{\mathrm{ad}}, X_{\mathrm{aq}}, X_{\mathrm{d}}^{\prime}, X_{\mathrm{q}}^{\prime}$, $X_{\mathrm{d}}^{\prime \prime}, X_{\mathrm{a}}^{\prime \prime}$ leakage, synchronous, stator reaction, transient and subtransient reactances in d- and q-axis, $T_{\mathrm{do}}^{\prime}, T_{\mathrm{do}}^{\prime \prime}$, $T_{\mathrm{qo}}^{\prime}, T_{\mathrm{qo}}^{\prime \prime}$ transient, subtransient time constants in d- and $\mathrm{q}$-axis at open generator stator winding.

This model was implemented in the program Matlab/Simulink.

In the model GENROU, the transformation voltage in the stator is neglected, one damping circuit in the d-axis and two damping circuits in the q-axis in the rotor are taken into account as well as the saturation of magnetic cores from the main magnetic field is included. Neglecting the transformation voltage of the stator results in algebraization of the stator equations and lowering the order of the differential equations of the model. These models are often used for simulation investigations of slowvariable, electromechanical transient states in power systems aiming at, $e g$, assessment of the angular stability of the system.

The appropriate selection of a test and measurement signals makes it possible to separate the investigated element of a generating unit (eg the synchronous generator) by reducing or eliminating the impact of other elements (eg the excitation system and the turbine) of the generating unit, thereby simplifying the process of estimating its parameters.

The stator axial voltages $V_{\mathrm{d}}, V_{\mathrm{q}}$, the field voltage $E_{\mathrm{fd}}$ and the rotor speed $\omega$ were assumed to be the input signals of the generator model, whereas the stator axial currents $I_{\mathrm{d}}, I_{\mathrm{q}}$ and the excitation current $I_{\mathrm{fd}}$ were assumed to be the output signals (Fig. 2).

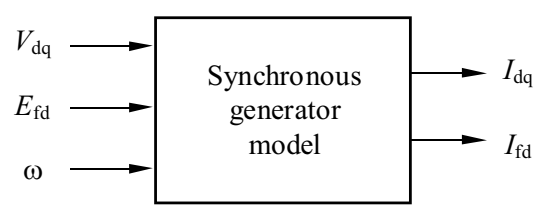

Fig. 2. Signals taken into account in the parameter estimation of the synchronous generator model

Parameters of the generator model were estimated using an iterative method in such a way that the dynamic waveforms calculated based on those parameters approximated the measured waveforms with a given accuracy. Changing algorithmically those parameters one should approach the given approximated waveforms resulting from the measurement tests performed. Calculations of the generator parameters were performed by minimizing the deviations of the simulation and measurement output waveforms in an appropriately selected time interval.

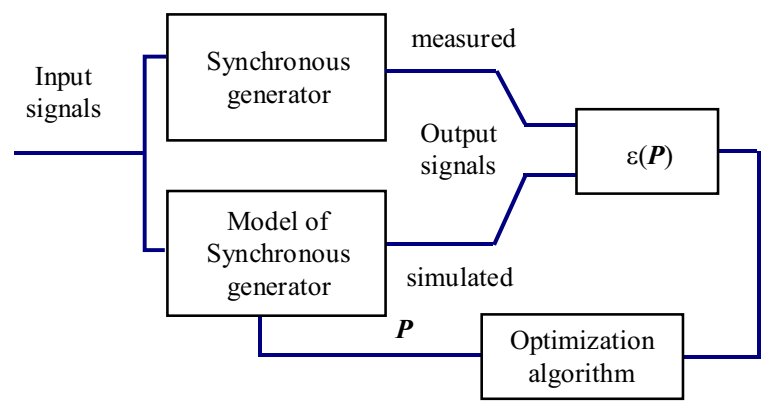

Fig. 3. Synchronous generator parameter estimation algorithm

The generator model parameter estimation was performed by the least squares method. In the estimation process, these parameters are selected in such a way as to minimize the mean square error defined for deviations (determined in the $i$-th time instants) between the measured waveforms (filtered from the noise) and the waveforms calculated on the basis of the mathematical model according to the relationship $[9,12]$

$$
\begin{aligned}
\varepsilon(\boldsymbol{P})=\frac{1}{2} \sum_{i=1}^{n}\left|\frac{I_{\mathrm{d} i}^{m}-I_{\mathrm{d} i}^{s}(\boldsymbol{P})}{I_{\mathrm{d} i}^{m}}\right|^{2}+ \\
\left.\left|\frac{I_{\mathrm{fd} i}^{m}-I_{\mathrm{fd} i}^{s}(\boldsymbol{P})}{I_{\mathrm{fd} i}^{m}}\right|^{2}+\left|\frac{I_{\mathrm{q} i}^{m}-I_{\mathrm{q} i}^{s}(\boldsymbol{P})}{I_{\mathrm{q} i}^{m}}\right|^{2}\right),
\end{aligned}
$$

where index $m$ denotes the filtered instantaneous values of the stator currents (in d- and q-axis) and the excitation current, index s denotes the simulated waveforms of these quantities calculated for the vector of the searched parameters:

$\boldsymbol{P}=\left[X_{\mathrm{d}}, X_{\mathrm{q}}, X_{\mathrm{d}}^{\prime}, X_{\mathrm{d}}^{\prime \prime}, X_{\mathrm{q}}^{\prime}, X_{\mathrm{q}}^{\prime \prime}, T_{\mathrm{do}}^{\prime}, T_{\mathrm{do}}^{\prime \prime}, T_{\mathrm{qo}}^{\prime}, T_{\mathrm{qo}}^{\prime \prime} X_{\sigma}^{\prime}, R_{\mathrm{a}}\right]$.

The minimization of the objective function (1) is a nonlinear problem. It can be solved by numerical methods with the use of different optimization algorithms, eg gradient, genetic or hybrid algorithm. Gradient algorithms belong to the local optimization algorithms so to 
obtain correct results, one should carefully choose the initial set of parameters. If we do not have sufficient knowledge about the values of the searched parameters, the extremum of the objective function is often determined by a genetic algorithm. A genetic algorithm uses mechanisms inspired by biological evolution, such as inheritance, mutation selection (survival of the fittest) and crossover. In most cases, this algorithm finds a solution close to the global optimum. If the solution thus obtained is still unsatisfactory, one can use a hybrid algorithm combining genetic and gradient algorithms. The use of a genetic algorithm in the first stage of calculations eliminates the need to precisely determine a starting point, whereas the use of a gradient algorithm in the second stage results in more accurate determination of the searches parameters. In the paper, there are presented the results of parameter estimation of the synchronous generator model by the hybrid algorithm.

\section{DESCRIPTION OF THE LABORATORY STAND}

The laboratory stand installed in the Institute of Electrical Engineering and Computer Science of SUT consists of a GCd 84b synchronous generator $\left(P_{\mathrm{n}}=44 \mathrm{~kW}, V_{\mathrm{n}}\right.$ $\left.=400 \mathrm{~V}, \cos \varphi_{\mathrm{n}}=0.8, n_{\mathrm{n}}=1500 \mathrm{rot} / \mathrm{min}\right)$ and a dc separately excited motor $\left(P_{\mathrm{n}}=55 \mathrm{~kW}, V_{\mathrm{n}}=220 \mathrm{~V}\right.$, $\left.I_{\mathrm{n}}=215 \mathrm{~A}, n_{\mathrm{n}}=1480 \mathrm{rot} / \mathrm{min}\right)$ driving the generator. The electromachine unit shown in Fig. 4 was mechanically connected by a flexible coupling.

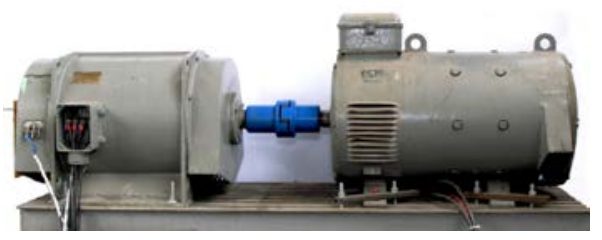

Fig. 4. The electromachine unit for investigations of a synchronous generator

The dc motor is supplied by a three-phase induction regulator through a six-pulse diode rectifier. The excitation circuit of the dc motor is supplied from a single phase autotransformer through a diode rectifier.

The stand is equipped with two control systems independent of each other. They are called automatic control and manual control. The switch is used to select the control mode. The manual control is used during the starting of the electromachine unit. In this mode of operation, the generator excitation current $I_{\mathrm{f} d}$ is a quantity being controlled. The excitation current value is adjusted by means of the potentiometer. After synchronizing the generator with the power system, the system switches to the automatic mode. In this mode, the reference value of the generator voltage is set manually by means of two potentiometers used for initial and precise setting.
The control system is equipped with a pulse width modulator (PWM) and modules protecting IGTB power transistors against overload and lack of voltage supplying the control system.

In the case of overload, the protection module disables the PWM modulator. Switching on makes the modulator work again. The module supply system contains galvanically isolated drivers of IGTB transistors.

Under normal operating conditions of a generating unit, the synchronous generator voltage regulator is to maintain an appropriate level of the stator voltage under changing load [21] as well as to damp slow-variable power swings [22]. For this reason, the voltage regulator installed on the test stand is equipped with an additional input to which a power system stabilizer or an additional signal source can be connected. Moreover, the voltage regulator limits overvoltages that may occur during emergency disconnection of the generator from PS. Such a situation occurs eg during power rejection. The upper limit of the voltage regulator output signal is selected in such a way that the full activation of IGTB power transistors corresponds to the maximum value of the output signal.

Because of the safety of service and elimination of common ground couplings, it was decided that all measuring instruments used on the test stand should be galvanically isolated.

Figure 5 shows the schematic diagram of the measuring part and the way of data acquisition on the stand. Four high-voltage Tektronix P5205 active probes (VP) of variable gain were used as generator stator and field voltage converters.

Three TCP404XL current probes (CP) with a TCPA V400 amplifier were used for measurement of the stator currents. The generator excitation current was measured by means of a TCP0030 current probe. Measurement of the rotor position was realized basing on a 2048 pulses per revolution rotary encoder. The encoder (E) output signal was fed to a signal microprocessor generating information on the rotor position.

Three Tektronix digital oscilloscopes of DPO4034, DPO3034, DPO2024 type were used for recording the waveforms. The field voltage was a rectangle wave signal with a variable pulse width (50-100\%) due to the generator excitation system which operated with pulse width modulation. For that reason, one of the oscilloscopes operated in the signal averaging mode.

\section{DETERMINATION OF THE TESTED GENERATOR MODEL PARAMETERS}

The measurements were made when introducing an additional disturbance signal in the form of the pseudorandom signal PRBS to the generator voltage regulator during the steady operation of the generator with the power system. That signal forced the changes of the voltage regulator reference voltage. During the measurements, the generator was loaded with the active power $P \approx 0.2$ and reactive power $Q \approx 0.1$ (in relative units). 


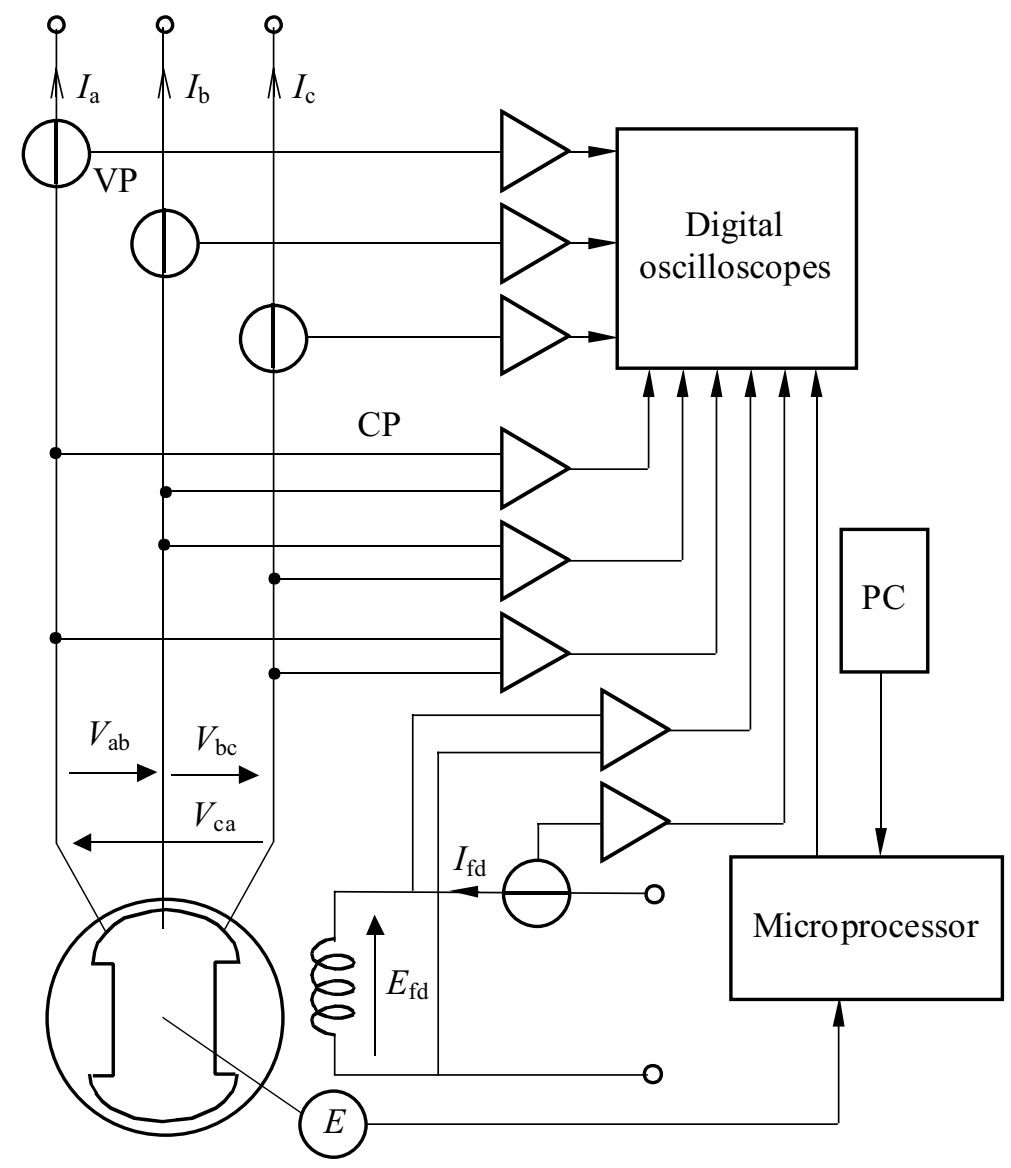

Fig. 5. Schematic diagram of the measuring part and the way of data acquisition of the tested synchronous generator

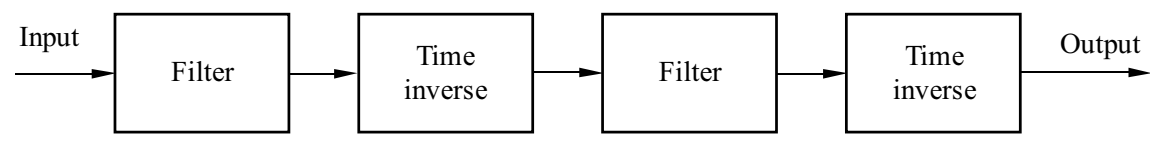

Fig. 6. Schematic diagram of zero-phase filtering

Table 1. Parameter estimation results for the pseudorandom signal

\begin{tabular}{ccccccc}
\hline Parameter & $X_{\mathrm{d}}$ & $X_{\mathrm{q}}$ & $X_{\mathrm{d}}^{\prime}$ & $X_{\mathrm{d}}^{\prime \prime}$ & $X_{\mathrm{q}}^{\prime}$ & $X_{\mathrm{q}}^{\prime \prime}$ \\
value & 1.625 & 0.82 & 0.26 & 0.23 & 0.58 & 0.57 \\
\hline Parameter & $T_{\mathrm{d} 0}^{\prime} / \mathrm{s}$ & $T_{\mathrm{d} 0}^{\prime \prime} / \mathrm{s}$ & $T_{\mathrm{q} 0}^{\prime} / \mathrm{s}$ & $T_{\mathrm{q} 0}^{\prime \prime} / \mathrm{s}$ & $X_{\sigma}$ & $R_{\mathrm{a}}$ \\
value & 0.955 & 0.176 & 0.005 & 0.0003 & 0.075 & 0.022 \\
\hline
\end{tabular}

The measured waveforms, being the basis of the tested generator parameter estimation, were strongly disturbed. To make the parameter estimation process run efficiently and smoothly, these waveforms have to be processed numerically, which aims at pre-processing and filtration of disturbances.

When analyzing the symmetrical transient states of the generator for which the stator star point is not grounded, the zero component is equal to zero. The voltages and currents of the stator expressed in the d,q coordinate system as well as the field voltage and excitation current of the generator contain mainly a constant com- ponent. That is why, there was used a low-pass filter for filtration.

Each filter introduces a non-zero phase shift unwanted from the point of view of parameter estimation. To eliminate the delays introduced by the filter, there was used a zero-phase shift filtering system. The filtration consists in filtering a signal twice by the same filter and two-fold reversing the signal time sequence. It aims at restoring the original order of the samples consistent with the input signal $[14,23]$. Fig. 6 shows the schematic diagram of zero-phase filtering.

A Butterworth filter [24] in the proposed zero-phase filtering system was used for filtration of the waveforms recorded in the laboratory. This filter was designed using Matlab Filter Design Toolbox [25]. Its parameters were individually selected for the recorded measurement waveforms.

Figures 7 and 8 show the measured and filtered waveforms of the axial components of the generator stator voltages and currents expressed in generator relative units as well as the measured waveforms of the field voltage 

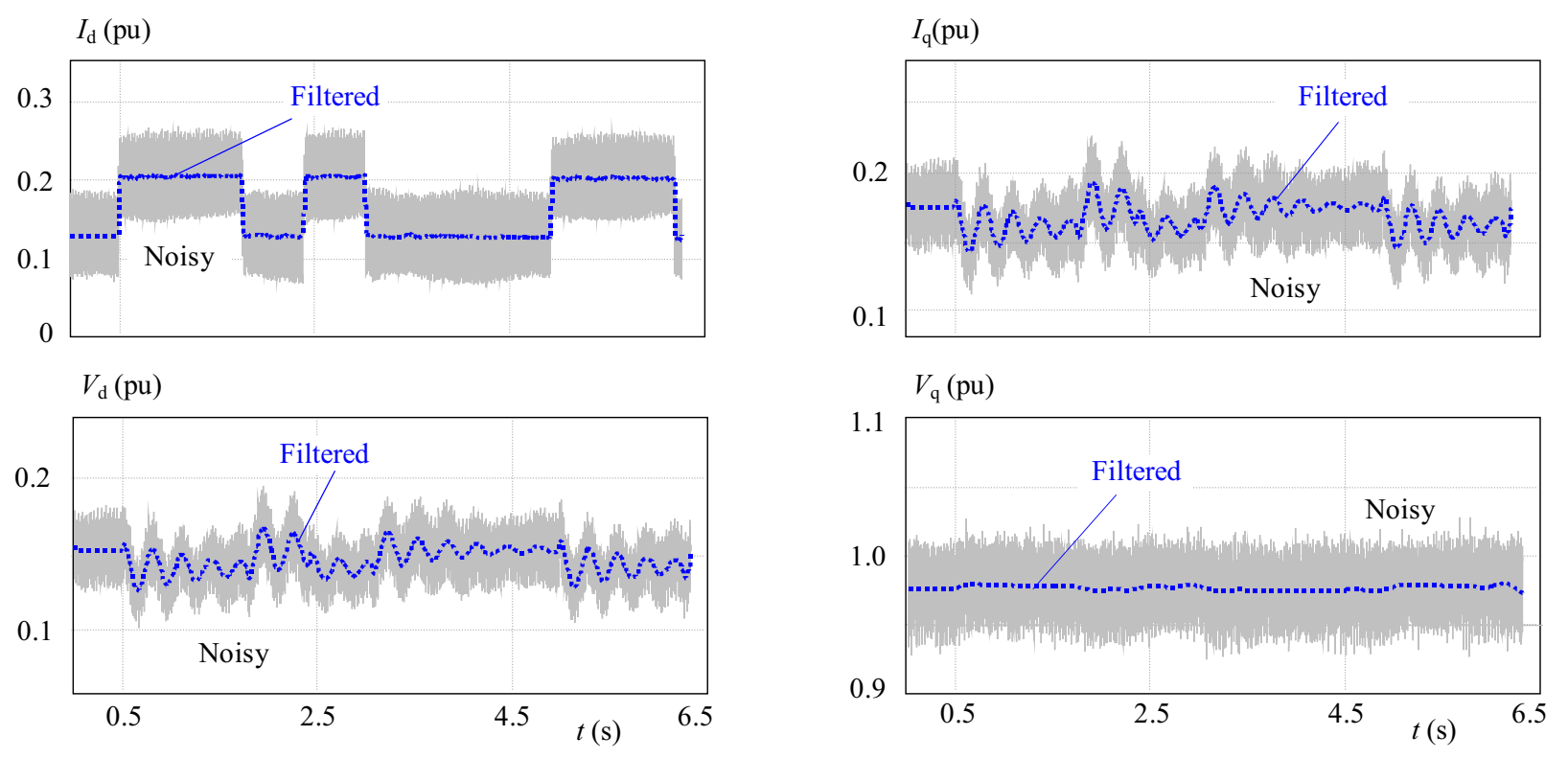

Fig. 7. Waveforms of the axial components of the generator stator voltages and currents and excitation current for disturbing the machine steady operation with a PRBS signal
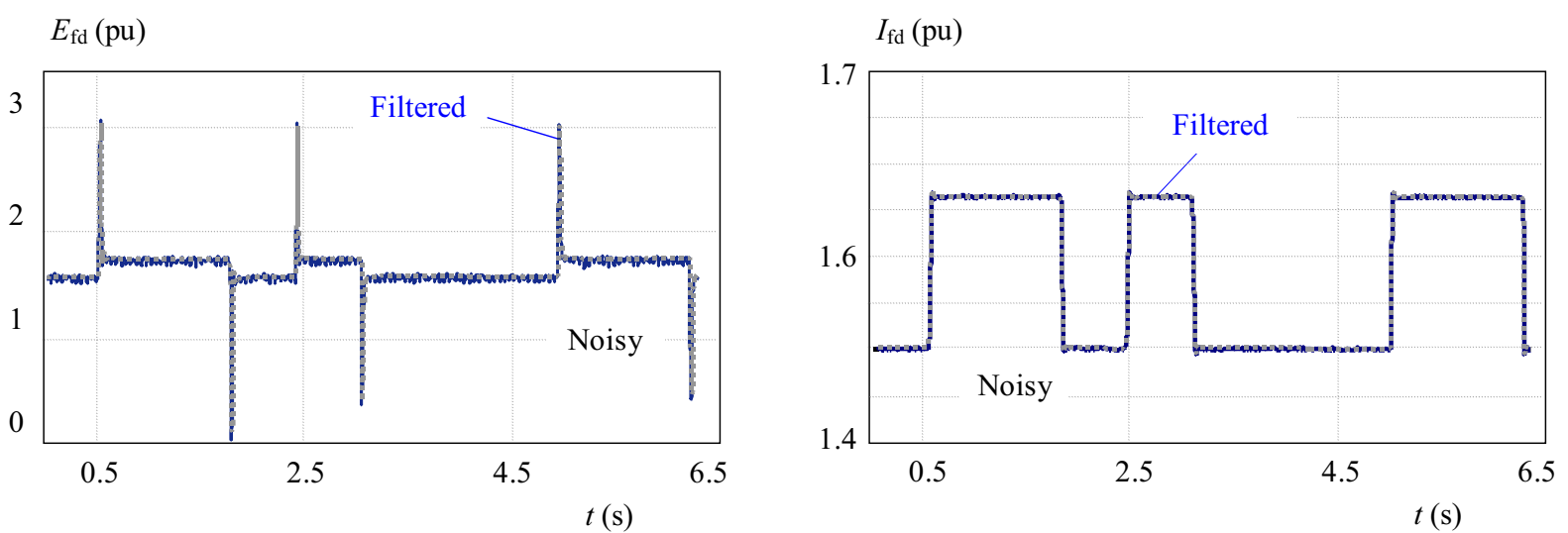

Fig. 8. Waveforms of the generator field voltage and excitation current for disturbing the machine steady operation with a PRBS signal

and the excitation current expressed in regulator relative units [15]. It can be noted that the envelopes of the signals were undistorted and synchronized in time with the original (non-filtered) signal, whereas a significant part of the disturbances was effectively filtered by the proposed zero-phase system.

Minimization of the objective function defined by formula (1) was performed in two stages using a hybrid algorithm. This algorithm is a combination of genetic and gradient algorithms [26]. In the first calculation stage, a genetic algorithm was used. The binary coding system and the tournament method as a way of selecting were used when applying the genetic algorithm. The basic parameters of the genetic algorithm were as follows: population size $=40$, maximum number of generations $=150$, crossover probability $=0.8$, mutation probability $=0.01$.

In the second stage of calculations, the parameters calculated by the genetic algorithm were assumed to be the starting point for a gradient algorithm. The parameters calculated that way are given in Table 1 . Figure 9 presents the comparison of the measured waveforms of the axial components of the stator currents and the excitation current (Measurement) with the waveforms calculated by means of the simulation model of the synchronous generator (Pestym).

\section{SUMMARY AND CONCLUSIONS}

In the paper, the description of the laboratory stand and the electromagnetic parameter estimation results of the synchronous generator model GENROU determined based on the measured transient waveforms have been presented. The recorded waveforms, being the basis of the parameter estimation, were strongly disturbed. To make the parameter estimation process run efficiently and smoothly, these waveforms were numerically processed, which aimed at pre-processing and filtration of disturbances. 

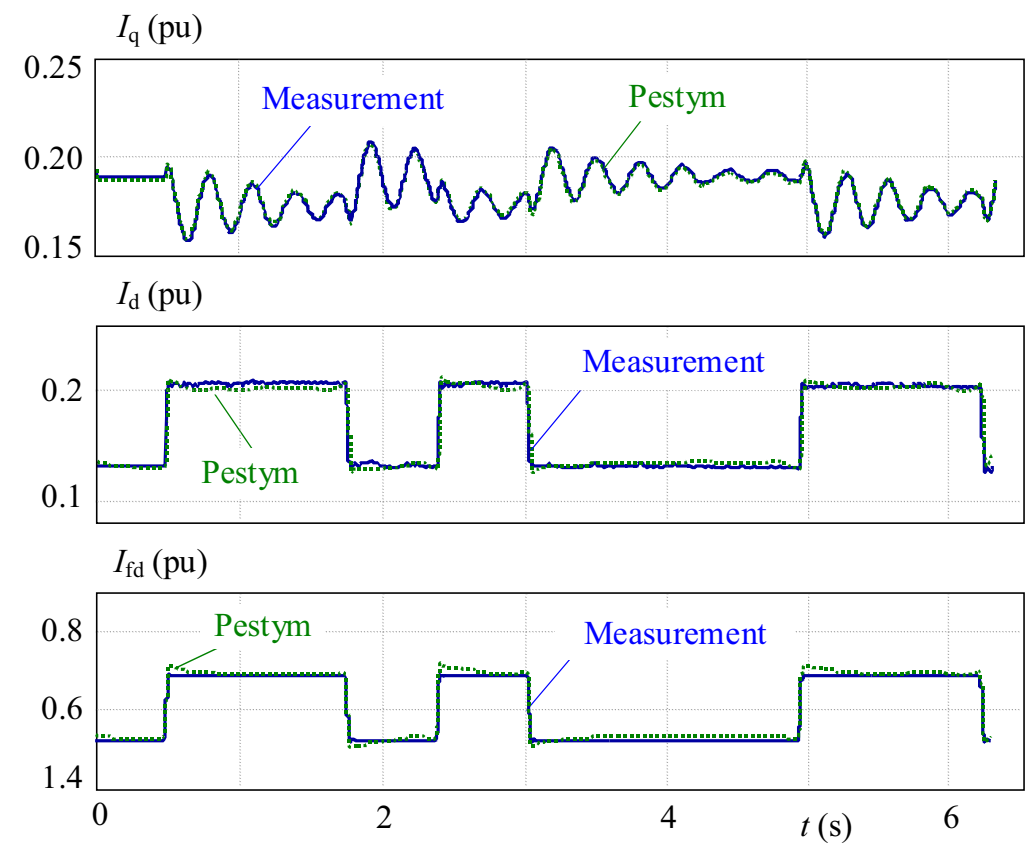

Fig. 9. Comparison of the measured waveforms of the axial components of the stator currents and excitation current with the waveforms calculated based on the circuit mathematical model of the synchronous generator

The least squares method was used for the estimation, and the hybrid algorithm, being the combination of genetic and gradient algorithms, was used for the minimization of the objective function.

To verify the correctness of the calculated generator parameters (see Table 1), there was determined the synchronous reactance in the d-axis on the basis of the measured steady-state no-load and three-phase symmetrical short-circuit characteristics of the generator. The value obtained was $X_{\mathrm{d}} \approx 1.582$ (in relative units). Also the ratio of the synchronous reactances in both axes, $X_{\mathrm{q}} / X_{\mathrm{d}} \approx 0.51$, was determined by the small slip method [27]. The value of the generator stator resistance obtained from the technical method was $R_{\mathrm{a}} \approx 0.0209$ (in relative units).

Therefore, it can be concluded that a good convergence of the generator model parameter estimation results was obtained when using different measuring methods.

The presented estimation method using a pseudorandom signal can be successfully applied to parameter estimation of different models of high-power synchronous generators operating in a power system.

\section{REFERENCES}

[1] IEEE Guide: Test Procedures for Synchronous Machines, IEEE Standard $115-2009$.

[2] IEEE Standard Procedures for Obtaining Synchronous Machine Parameters by Standstill Frequency Response Testing, IEEE Standard 115A-1987, (1987).

[3] CISNEROS-GONZLEZ, M.-HERNANDEZ, C.-MORALESCAPORAL, R.-BONILLA-HYERTA, E.-ARJONA, M. A.: Parameter estimation of synchronous-generator two-axis model based on the chirp test, IEEE Transactions on Energy Conversion 28 No. 1 (2013), 44-51.
[4] MAJKA, L.-SZUSTER, D. : Application of the stationary DC decay test to industrial turbogenerator model parameter estimation, Przegląd Elektrotechniczny 90 No. 4 (2014), 242-245.

[5] Ahmed, M.-OTEAFY, A.-ChiAsson, J. N. : A Standstill Parameter Identification Technique for the Divided Winding Rotor Synchronous Generator, 2014 IEEE International Conference Power \& Energy, 1-3 Dec. 2014,, 99-104.

[6] JAhromi, M. E.-FIROUZI, B.-RANJBAR, A. M. : Possibility of Large Synchronous Generator Parameters Estimation via On-Line Field Tests using Genetic Algorithm, Power India Conference, IEEE, 2006.

[7] TANPO, S.-OHISHI, K.-MAKISHIMA, S.-UEZONO, K. : Online Identification and Tuning Method of Static \& Dynamic Inductance of IPMSM for Fine Position Sensorless Control, 2014 IEEE, International Conference on Industrial Technology, Feb. 26 - Mar. 1, Busan, Korea.

[8] IEEE Std 1110-2002: IEEE Guide for Synchronous Generator Modeling Practices and Applications in Power System Stability Analyses, 2003.

[9] JAhromi, M. E.-FIROUZI, B.-RANJBAR, A. M. : Possibility of large synchronous generator parameters estimation via on-line field tests using genetic algorithm, Power India Conference, 2006 IEEE.

[10] AHMADI, S.-KARRARI, M. : A Multiple-Model Approach for Synchronous Generator Nonlinear System Identification, Journal of Electrical Engineering 63 No. 4 (2012), 249-254.

[11] KYRIAKIDES, E.-HEYDT, G. T-VITTAL, V.: Online parameter estimation of round rotor synchronous generators including magnetic saturation, IEEE Transactions on Energy Conversion 20 No. 3 (2005), 529-537.

[12] BERHAUSEN, S.-PASZEK, S. : Parameter Estimation of the Model of a Synchronous Generator Working in Multi-Machine Power System. (in Polish)

[13] WAMKeue, R.-BAETSCHER, F.-KAMWAI.: Hybridstate-model-based time-domain identification of synchronous machine parameters from saturated load rejection test records, IEEE Transactions on Energy Conversion 23 No. 1 (2008), 68-77.

[14] BERHAUSEN, S.-PASZEK, S.: Assessment of the accuracy of synchronous generator model parameter estimation based on 
noisy dynamic waveforms, Przegld Elektrotechniczny 91 No. 7 (2015), 16-20.

[15] PASZEK, S.-BERHAUSEN, S.-BOBOŃ, A.-MAJKA, E.NOCOŃ, A.-PASKO, M.-PRUSKI, P.-KRASZEWSKI, T. : Measurement Estimation of Dynamic Parameters of Synchronous Generators and Excitation Systems Working in the National Power Plant, Monograph, Wyd. Politechniki Śląskiej, Gliwice, 2013. (in Polish)

[16] SIMOND, J. J.-RAMIREZ, C.-TUXUAN, M.-STEPHAN, C. E.: A numerical test platform for large synchronous machines also useful as a design optimization tool, IEEE Power Engineering Society General Meeting (2006), 1-7.

[17] BERHAUSEN, S.-PASZEK, S.: Use of the finite element method for parameter estimation of the circuit model of a high power synchronous generator, Bulletin of the Polish Academy of Sciences Technical 63 No. 3 (Sep. 2015), 575-582.

[18] VERMEUlEN, H. J.-STRAUSS, J. M.-SHIKOANA, V. : Online Estimation of Synchronous Generator Parameters using PRBS Perturbations, IEEE Transactions on Power Systems 17 No. 3 (2002), 674-700.

[19] ZAKER, B.-CHAREHPETIAN, G. B.-KARRARI, M.-MOADDABI, N.: Simultaneous Parameter Identification of Synchronous Generator and Excitation System Using Online Measurements, IEEE Transactions on Smart Grid PP No. 99 (2015), $1-9$.

[20] DE MELlO, F. P.-HANNETT, L. H. : Validation of Synchronous Machine Models and Derivation of Model Parameters from Tests, IEEE Transaction on Power Apparatus and Systems 100 No. 2 (1981), 662-672.

[21] MACHOWSKI, J.-BIALEK, J. W.-BUMBY, J. R. : Power System Dynamice, Stability and Control, John Wiley \& Sons, New York, 2008.

[22] VESELÝ, V.-QUANG, T. : Robust Power System Stabilizer via Networked Control System, Journal of Electrical Engineering 62 No. 5 (2011), 286-291.
[23] KORMYLO, J.-JAIN, V.: Two-Pass Recursive Digital Filter with Zero Phase Shift, IEEE Transactions on Acoustics, Speech, and Signal Processing 22 No. 5 (1974), 384-387.

[24] LYONS, R. G. : Understanding digital signal processing, Prentice Hall, Upper Saddle River,3rd edition, 2010.

25] Mathworks Inc.: MATLAB, Signal Processing Toolbox User's Guide, (2001).

[26] MAJKA, L.-PASZEK. S. : Use of hybrid optimization algorithm for electromagnetic parameter estimation of a synchronous generator, Prace Naukowe Politechniki Śla̧skiej, Elektryka No. 2(210) (2009), 17-22.

[27] BOLDEA, I. : Synchronous Generators, CRC Press, Taylor and Francis Group, 2006.

Received 14 September 2015

Sebastian Berhausen works at the Institute of Electrical Engineering and Computer Science, Silesian University of Technology. His research interests include: parameter estimation of generating unit models, modeling, analysis and simulation of AC electrical machines in steady and transient states, finite element analysis of electromagnetic field distributions in electrical machines and devices. Author and co-author of 36 publications, including a monograph.

Stefan Paszek works at the Institute of Electrical Engineering and Computer Science, Silesian University of Technology. His research interests include: power system analysis in transient states, power system angle stability, optimisation and polyoptimisation of system stabilizers and voltage regulators of synchronous generators, estimation of parameters of generating unit models in power system, new models of synchronous generators using the artificial neural network technology, application of fuzzy controllers in electric machines regulation systems. Author and co-author of 171 publications, including five monographies and co-author of three academic textbooks. 